\title{
Radiative Transfer Simulations Using Mesoscale Cloud Model Outputs: Comparisons with Passive Microwave and Infrared Satellite Observations for Midlatitudes
}

\author{
Ingo Meirold-Mautner, Catherine Prigent, And Eric Defer \\ LERMA, Observatoire de Paris, Paris, France \\ JUAN R. PARDO \\ CSIC, Universidad de Madrid, Madrid, Spain \\ Jean-Pierre Chaboureau and Jean-Pierre Pinty \\ Laboratoire d'Aérologie, Université Paul Sabatier and CNRS, Toulouse, France \\ Mario Mech and Susanne CRewell \\ Meteorological Institute, University of Munich, Munich, Germany
}

\begin{abstract}
Real midlatitude meteorological cases are simulated over western Europe with the cloud mesoscale model Méso-NH, and the outputs are used to calculate brightness temperatures at microwave frequencies with the Atmospheric Transmission at Microwave (ATM) radiative transfer model. Satellite-observed brightness temperatures (TBs) from the Advanced Microwave Scanning Unit B (AMSU-B) and the Special Sensor Microwave Imager (SSM/I) are compared to the simulated ones. In this paper, one specific situation is examined in detail. The infrared responses have also been calculated and compared to the Meteosat coincident observations. Overall agreement is obtained between the simulated and the observed brightness temperatures in the microwave and in the infrared. The large-scale dynamical structure of the cloud system is well captured by Méso-NH. However, in regions with large quantities of frozen hydrometeors, the comparison shows that the simulated microwave TBs are higher than the measured ones in the window channels at high frequencies, indicating that the calculation does not predict enough scattering. The factors responsible for the scattering (frozen particle distribution, calculation of particle dielectric properties, and nonsphericity of the particles) are analyzed. To assess the quality of the cloud and precipitation simulations by Méso-NH, the microphysical fields predicted by the German Lokal-Modell are also considered. Results show that in these midlatitude situations, the treatment of the snow category has a high impact on the simulated brightness temperatures. The snow scattering parameters are tuned to match the discrete dipole approximation calculations and to obtain a good agreement between simulations and observations even in the areas with significant frozen particles. Analysis of the other meteorological simulations confirms these results. Comparing simulations and observations in the microwave provides a powerful evaluation of resolved clouds in mesoscale models, especially the precipitating ice phase.
\end{abstract}

\section{Introduction}

A strong need is emerging to have accurate radiative transfer simulations from realistic cloudy and rainy scenes at high microwave frequencies. First, efforts are made to assimilate satellite microwave radiation from

Corresponding author address: Dr. Catherine Prigent, LERMA, Observatoire de Paris 61, av. de l'Observatoire, 75014 Paris, France.

E-mail: catherine.prigent@obspm.fr cloudy and rainy atmospheres within numerical weather prediction (NWP) models. As a first step, precipitation affected satellite observations at microwave frequencies up to $22 \mathrm{GHz}$ are assimilated in the European Centre for Medium-Range Weather Forecasts (ECMWF) model since June 2005 (Bauer et al. 2005). At these low microwave frequencies, the hydrometeors essentially interact with the radiation through emission and absorption and these effects can be taken into account in the radiative transfer model with simplifying assumptions. Current satellite observations in the mi- 
crowave domain are available up to $190 \mathrm{GHz}$. Contrarily to the low-frequency range, high microwave frequencies can be significantly scattered by hydrometeors, and the relationship between radiation and clouds becomes much more complex: the radiative transfer calculations are more difficult to handle when scattering is involved, and they strongly depend upon a detailed description of the cloud microphysics parameterizations that are not currently available in NWP models. To assimilate the higher frequencies in NWP models in cloudy situations, it is necessary to develop and evaluate adequate radiative transfer models along with cloud microphysics parameterizations. Second, studies show that satellite measurements in the millimeter and submillimeter could help supplement the infrared and the visible observations in the characterization of the cloud ice phase (Evans et al. 2002, 2005) and satellite projects are planned to explore this frequency range (e.g., Buehler 2005). In addition, the potential of this wavelength domain for precipitation estimates is also under investigation. Optimum temporal sampling of the rain events could be obtained from geostationary satellite, but from these high orbits, low microwave frequencies would not provide the adequate spatial resolutions and millimeter and submillimeter wavelengths are examined (Crewell et al. 2005; Prigent et al. 2005c; Mech et al. 2006, manuscript submitted to IEEE Trans. Geosci. Remote Sens.). Spaceborne millimeter and submillimeter wave observations being very scarce-a few aircraft measurements for a limited set of frequencies and a few situations - analysis of the feasibility of ice cloud and precipitation retrievals from this frequency range can only be performed through the use of simulated datasets.

As a consequence, simulations of realistic radiances of cloudy and rainy situations are strongly required at high microwave frequencies, implying that representative cloud model outputs along with accurate radiative transfer (RT) models exist. At frequencies above 37 $\mathrm{GHz}$ when scattering by hydrometeors is present, accurate simulations of precipitating clouds require a detailed description of the atmospheric column (including the characteristics of the different water and ice particles), which are available from mesoscale cloud models. Note that the large-scale evaluation of simulated cloudy radiances has also been suggested using modelto-satellite approaches: radiances are simulated using outputs from an atmospheric model and compared to satellite observed radiances for the same situations (e.g., Chevallier et al. 2001; Chaboureau et al. 2000, 2002). In the framework of the Tropical Rainfall Measuring Mission (TRMM), a database of simulated brightness temperatures has been developed at TRMM
Microwave Instrument (TMI) frequencies (from 10 to $85 \mathrm{GHz}$ ) for typical tropical situations, from detailed mesoscale cloud model outputs. Many TRMM rain algorithms are related to this dataset named GPROF (Kummerow et al. 2001). Its representativeness for tropical situations has been tested statistically: it has been checked that the shape of the distribution of the simulated and observed brightness temperatures (TBs) agreed, but to our knowledge direct comparisons between simulated and observed TBs for specific meteorological cases has not been published. Wiedner et al. (2004) directly compare radiative transfer simulation derived from mesoscale cloud model outputs with observations from TMI for two tropical situations. This study shows a good agreement between simulated and observed radiances up to $85 \mathrm{GHz}$. Given the high sensitivity of these frequencies to particle characteristics especially in the ice phase, this study is very encouraging in regard to both the accuracy of the radiative transfer model and the overall behavior of the bulk microphysical schemes for deep convective cloud systems. So far, most efforts on the analysis of cloudy and rainy situations in the microwave have been motivated by TRMM and, as a consequence, have concentrated on tropical latitudes and frequencies below $100 \mathrm{GHz}$. In this study, we propose to examine midlatitude cases with frequencies up to $190 \mathrm{GHz}$, using the same radiative transfer code and mesoscale cloud model as in Wiedner et al. (2004).

Recently, five real midlatitude cases have been simulated with the mesoscale cloud model Méso-NH, from stratiform precipitation at higher latitudes to convective precipitation in the Mediterranean region (J.-P. Chaboureau et al. 2006, unpublished manuscript). For each case, the model outputs are available at several time steps. All the relevant parameters especially those characterizing the frozen hydrometeors are available from the model output and are gathered in a database. Some RT calculations of these five situations were performed with the Atmospheric Transmission at Microwaves (ATM) model. The derived TBs have been compared to observations over a large spectral range covering 19 to $190 \mathrm{GHz}$ [the Special Sensor Microwave Imager (SSM/I) and the Advanced Microwave Scanning Unit (AMSU)]. In addition, to better analyze potential discrepancies between simulations and observations and to help separate errors from the RT and cloud model at mesoscale, infrared (IR) simulations and observations (Meteosat) will also be presented.

In this paper, the detailed evaluation of one selected midlatitude case is presented and only a brief summary of the other cases is given. Special emphasis is put on the analysis of the ice phase, which is particularly im- 
portant at high microwave frequencies. The mesoscale cloud model Méso-NH is described in section 2 along with characteristics of the main case under investigation. In section 3, the ATM microwave radiative transfer model is described. To evaluate the simulated TBs, observations from two microwave instruments are analyzed (SSM/I, AMSU) along with one IR instrument (Meteosat). The results of the comparison between observations and simulations are shown in section 4. A sensitivity study of the RT simulations on the hydrometeor characteristics is presented in section 5. Finally, section 6 concludes this study.

\section{The mesoscale cloud model: Méso-NH}

\section{a. Characteristics of the Méso-NH model}

The nonhydrostatic mesoscale cloud model MésoNH jointly developed by Météo-France and the Centre National de la Recherche Scientifique (CNRS) is used to simulate the atmospheric state for the selected precipitation cases. A detailed description of the Méso-NH is given in Lafore (1998). See the Méso-NH scientific documentation available online at http://mesonh.aero. obs-mip.fr/mesonh for a complete description of the model.

The mixed-phase microphysical scheme developed by Pinty and Jabouille (1998) essentially follows the approach of Lin et al. (1983): a three-class ice parameterization is used with a Kessler (1969) scheme for the warm processes. The scheme predicts the evolution of the mixing ratios of six water species: $r_{v}$ (vapor), $r_{c}$, and $r_{r}$ (cloud droplets and rain drops), and $r_{i}, r_{s}$, and $r_{g}$ (pristine ice, snow aggregates, and frozen drops graupel defined by an increasing degree of riming). The concentration of the pristine ice crystals is diagnosed. The concentration of the precipitating water drops, snow, and graupel is parameterized according to Caniaux et al. (1994), with the total number concentration $N$ given by

$$
N=C \lambda^{x},
$$

where $\lambda$ is the slope parameter of the size distribution, and $C$ and $x$ are empirical constants derived from radar observations. The size distribution of the hydrometeors is assumed to follow a generalized $\gamma$ law:

$$
n(D) d D=N g(D) d D=N \frac{\alpha}{\Gamma(\nu)} \lambda^{\alpha \nu} D^{\alpha \nu-1} e^{-(\lambda D)^{\alpha}} d D
$$

where $g(D)$ is the normalized form which reduces to the Marshall-Palmer law when $\alpha=\nu=1$ ( $D$ is the diameter of the drops or the maximal dimension of the particles). Finally, simple power laws are taken for the
TABLE 1. Characteristics of each hydrometeor category $\alpha$ and $\nu$ are used in Eq. (2). The other coefficients are related to powerlaw relationships for the mass $\left(m=a D^{b}\right)$, the fall speed $\left(v=c D^{d}\right)$, where $D$ is the particle size, and for the concentration in Eq. (1).

\begin{tabular}{cllcrr}
\hline \hline Parameters & $r_{i}$ & \multicolumn{1}{c}{$r_{s}$} & $r_{g}$ & $r_{c}$ & $r_{r}$ \\
\hline$\alpha$ & 3 & 1 & 1 & 3 & 1 \\
$\nu$ & 3 & 1 & 1 & 3 & 1 \\
$a$ & 0.82 & 0.02 & 19.6 & 524 & 524 \\
$b$ & 2.5 & 1.9 & 2.8 & 3 & 3 \\
$c$ & 800 & 5.1 & 124 & $3.2 \times 10^{7}$ & 842 \\
$d$ & 1.00 & 0.27 & 0.66 & 2 & 0.8 \\
$C$ & & 5 & $5 \times 10^{5}$ & & $10^{7}$ \\
$x$ & & 1 & -0.5 & & -1 \\
\hline
\end{tabular}

mass-size $\left(m=a D^{b}\right)$ and for the velocity-size $(v=$ $\left.c D^{d}\right)$ relationships to perform useful analytical integrations using the moment formula:

$$
M(p)=\int_{0}^{\infty} D^{p} g(D) d D=\frac{\Gamma(\nu+p / \alpha)}{\Gamma(\nu)} \frac{1}{\lambda^{p}},
$$

where $M(p)$ is the $p^{\text {th }}$ moment of $g(D)$. A first application of Eq. (3) is to compute the mixing ratio $r_{x}$ as

$$
\rho_{\mathrm{air}} r_{x}=a N M_{x}(b) .
$$

Table 1 provides the characterization of each ice category and cloud droplets/raindrops.

Méso-NH outputs include a full description of the atmospheric parameters (pressure, temperature, and mixing ratios for the water vapor, and the five hydrometeor categories). The multiple interactions operating between the different water categories are accounted for through the parameterization of 35 microphysical processes (nucleation, conversion, riming, sedimentation, etc.). More detailed information can be found in Wiedner et al. (2004).

\section{b. The case studied: A light precipitation at Hoek van Holland}

This case occurred on 19 September 2001 over northeastern France and Netherlands. It was a long lasting precipitation event produced by a quasi-stationary low pressure system. Maximum rainfall of $100 \mathrm{~mm}$ has been measured over the whole event at Hoek van Holland, Netherlands, with intensities of a few millimeters per hour.

Temperature, wind, surface pressure, water vapor, and sea surface temperature taken from the ECMWF 6-hourly analysis are used as initial and boundary conditions. The vertical grid has 50 levels up to an altitude of $20 \mathrm{~km}$, with layer thickness varying from $60 \mathrm{~m}$ close to the surface up to $600 \mathrm{~m}$. The horizontal grid spacing is $10 \mathrm{~km}$ and the domain cover $1600 \mathrm{~km} \times 1600 \mathrm{~km}$.

The model is initialized on 0000 UTC 19 September 


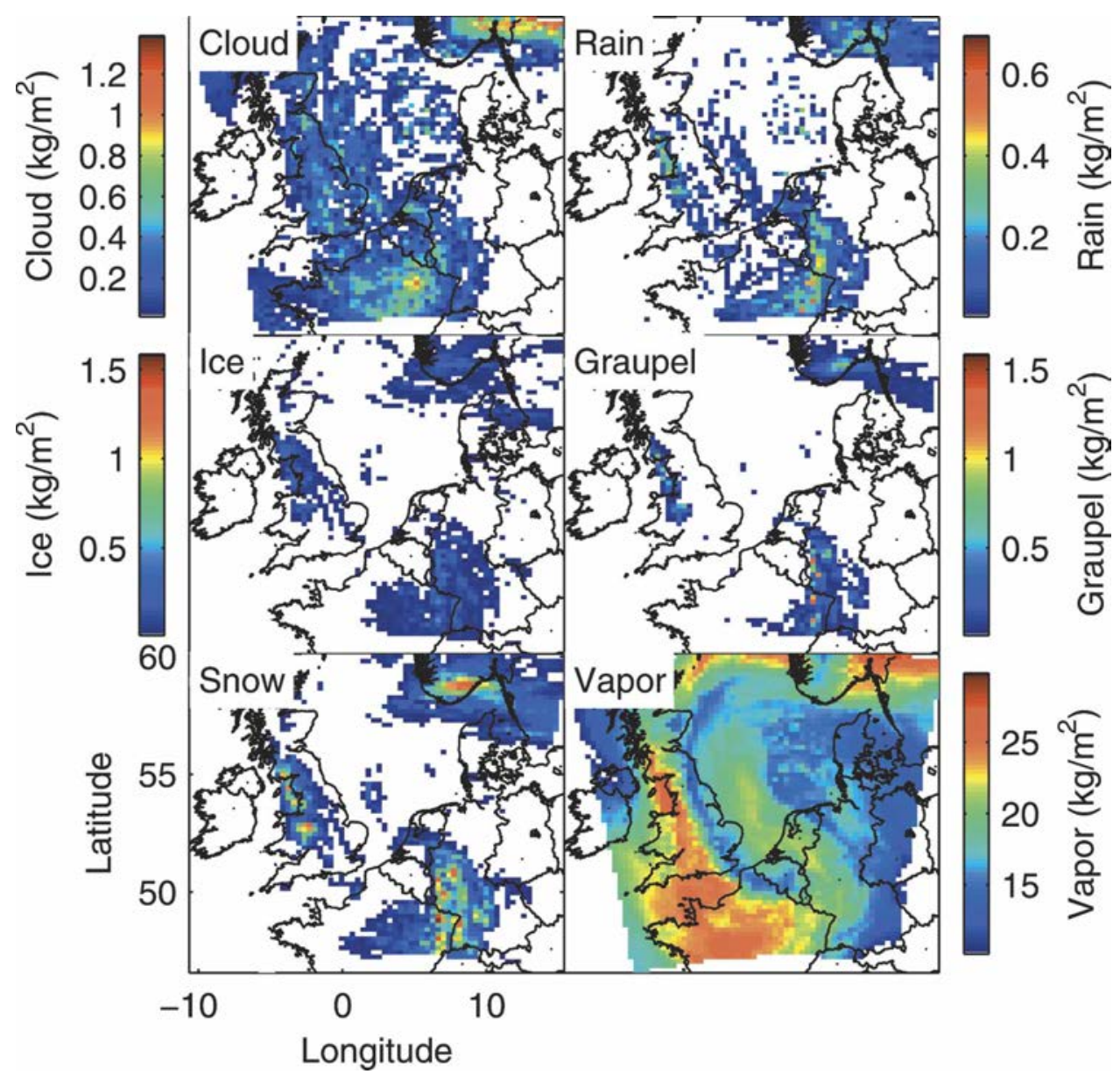

FIG. 1. Total integrated columns $\left(\mathrm{kg} \mathrm{m}^{-2}\right)$ of cloud, rain, ice, graupel, snow, and water vapor for the Hoek case at 1800 UTC. The color bar for snow is identical to the ice and graupel ones.

2001 and is integrated forward for $24 \mathrm{~h}$. Outputs at 1800 UTC are analyzed in this study. A representation of the total columns of liquid cloud, rain, ice, graupel, snow, and water vapor, as simulated by Méso-NH at 1800 UTC is shown in Fig. 1.

\section{The radiative transfer model: ATM}

The ATM model is composed of four basic parts: the absorption by atmospheric gases, the calculation of the scattering by hydrometeors, the estimation of the surface emissivity for both ocean and land, and the radiative transfer through an atmosphere with plane parallel layers in which different hydrometeors and/or atmospheric gases coexist.

The absorption by atmospheric gases is introduced in the model according to Pardo et al. (2001a). Line-byline calculations of the resonant part of the absorption are performed using a line atlas generated from the latest available spectroscopic constants for all relevant atmospheric species. The excess of absorption in the longwave range that cannot be explained by the resonant spectrum is modeled by introducing continuumlike terms. Using the spectroscopy described in Pardo et al. (2001a) and ground-based Fourier Transform Spectroscopy measurements, the continuum terms that have to be added to the line spectrum have been derived (Pardo et al. 2001b, 2004). The results are summarized in Pardo et al. (2005).

The RT model treats the scattering of radiation through layers of hydrometeors as described in Prigent et al. (2001, 2005b) and Wiedner et al. (2004). The absorption of atmospheric gases is first calculated in all layers with the clear sky routines, then the far field scattering by single spherical or nonspherical particles is computed with the T-matrix algorithm developed by Mishchenko (1991, 1993, 2000). Partially oriented nonspherical particles (provided that the orientation is random at least in azimuth) can be treated. The initial code has been modified to allow accurate scattering calcula- 
tions when several hydrometeor species are simultaneously present in a given layer. The different physical properties and distributions of the five types of hydrometeors defined by Méso-NH are taken into account, in order to perform the microwave radiative transfer for conditions that are as consistent as possible with the Méso-NH simulations. The impacts of particle parameters on the calculated brightness temperatures are discussed in section 5.

The RT model includes a full treatment of the effect of the surface (Lambertian or Fresnel-like surfaces) as well as a model to treat the wind-roughened ocean surface (Guillou et al. 1996). A land surface emissivity atlas derived from SSM/I and AMSU observations is attached to the model (Prigent et al. 1997, 2005a), along with angular and frequency parameterization. The final radiative transfer calculation is performed using the doubling and adding method as described in Evans and Stephens (1995).

\section{Comparison between satellite observations and simulations}

The microwave simulations are obtained at the model grid resolution; they are directly compared to the coincident SSM/I and AMSU satellite observations after convolution with the instrument antenna pattern (here approximated with Gaussian functions).

In addition, simulations corresponding to the Meteosat-7 channel in the thermal IR window (10.5-12.5 $\mu \mathrm{m}$, hereafter referred to as $11 \mu \mathrm{m}$ ) have also been calculated from the same Méso-NH outputs, using the Radiative Transfer for Television Infrared Observation Satellite (TIROS) Operational Vertical Sounder (TOVS) model (hereafter RTTOV; Eyre 1991) and are compared to Meteosat-7 observations at 1800 UTC over the same region. Also, IR at $11 \mu \mathrm{m}$ is a complementary source of cloud information: being essentially sensitive to the cloud top properties, the $11-\mu \mathrm{m}$ channel can clearly diagnose the cloud horizontal location in the Méso-NH simulation as well as the position of the cloud top. In the comparison process between simulated and observed microwave TBs, the $11-\mu \mathrm{m}$ channel helps separate the errors related to the microwave RT models from the errors due to the mesoscale cloud model outputs.

\section{a. The microwave satellite observations: SSM/I and AMSU}

Two different microwave instruments are used for this study: (i) SSM/I hosted by the Defense Meteorological Satellite Program's satellites and (ii) AMSU on board National Oceanic and Atmospheric Administration (NOAA) satellites. SSM/I is a conical scanning instrument with a constant viewing angle of $53^{\circ}$. It operates at frequencies between 19 and $85 \mathrm{GHz}$ with both horizontal $(\mathrm{H})$ and vertical $(\mathrm{V})$ polarizations detected. The elliptical fields of view decrease in size proportionally with frequency, from $43 \times 69 \mathrm{~km}$ at $19 \mathrm{GHz}$ to $13 \times 15 \mathrm{~km}$ at $85 \mathrm{GHz}$. In contrast, the AMSU is a cross-track scanning instrument with viewing zenith angles varying between $0^{\circ}$ and $58.5^{\circ}$. The frequency channels range from 23.8 to $89 \mathrm{GHz}$ (AMSU-A) and from 89 to $190 \mathrm{GHz}$ (AMSU-B). The spatial resolution at nadir is $48 \mathrm{~km}$ for AMSU-A and $16 \mathrm{~km}$ for AMSU-B. For a given instrument ( $\mathrm{A}$ or $\mathrm{B}$ ), the spatial resolution is fixed regardless of the frequency but it changes with the zenith angle. The polarization is variable and results from a combination of two orthogonal linear polarizations ( $\mathrm{V}$ and $\mathrm{H})$, and so depends on the scanning angle.

For the analysis of window channels, SSM/I presents the advantages of constant viewing angle and constant spatial resolution at a given frequency, as compared to the AMSU cross-track instrument. This facilitates the comparison between simulations and observations: the variability and uncertainty related to viewing angle and spatial resolution are suppressed. In addition, two orthogonal polarizations are available from SSM/I, making it easier to separate potentially polarized surface effects from the atmospheric contribution. Although this study focuses primarily on high frequency evaluation, comparison with SSM/I observations helps analyze the atmospheric situation and the differences between AMSU simulations and observations.

\section{b. The observed and simulated fields}

At first, observations from SSM/I at 1941 UTC and AMSU at 1755 UTC are compared to the simulated TB fields at 1800 UTC, along with the IR observed and simulated images (Fig. 2). A few qualitative remarks can be stated: 1) the global spatial structures are fairly well represented in the microwave and in the IR meaning that the mesoscale cloud model is able to reproduce the thermodynamic nature of the precipitating system, 2) the overall agreement between simulated and measured TBs in the microwave is reasonable, 3) a closer look at the figures in the microwave and in the IR reveals small displacements in the cloudy structures and discrepancies in the intensity of the radiative signatures. The microwave simulations show scattered cloud fields across the North Sea but the observations do not. In addition, the strong scattering signatures (TB depression) observed over central Germany/east France or south Norway appear in the simulations but with significantly less intensity, especially at higher window 


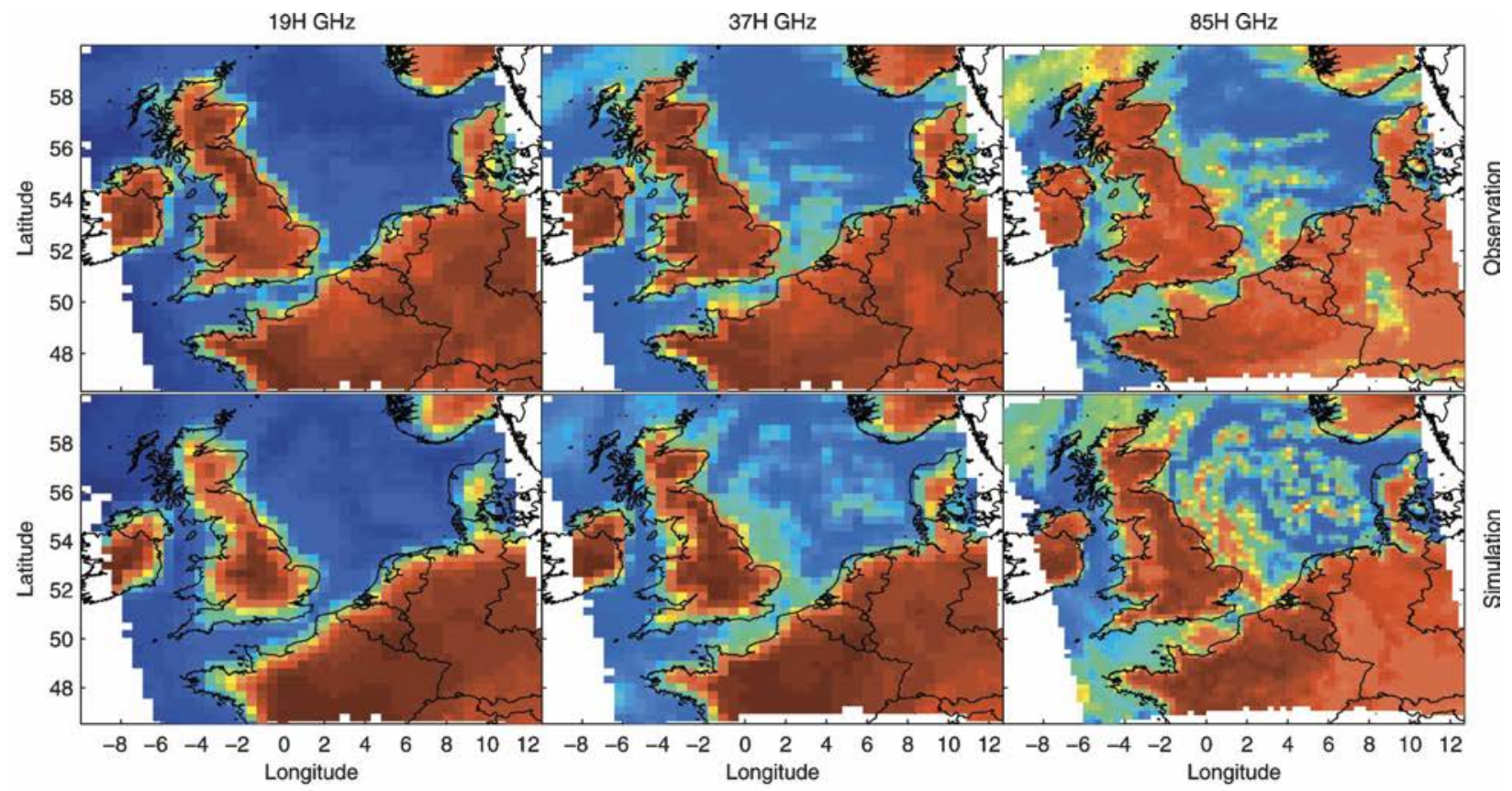

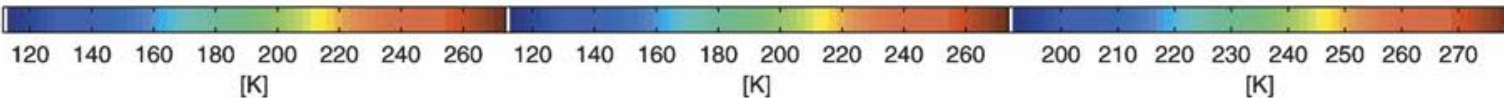

(a) SSM/I

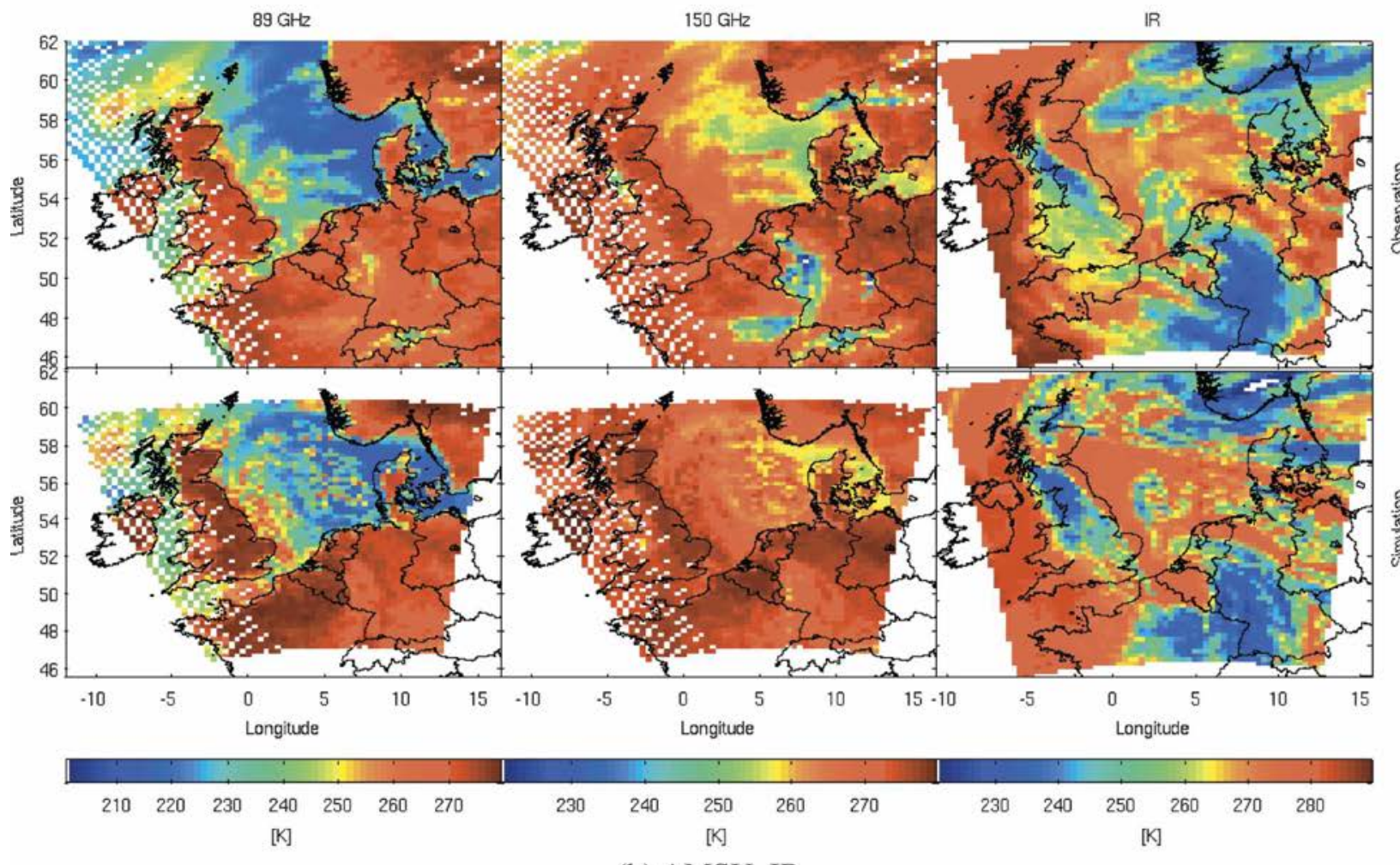

(b) AMSU, IR

FIG. 2. SSM/I, AMSU-B, and Meteosat IR observations for (top) the Hoek case compared to (bottom) simulations, for selected channels. The simulations take into account the scanning angles, the polarizations, and the fields of view of the instruments. 

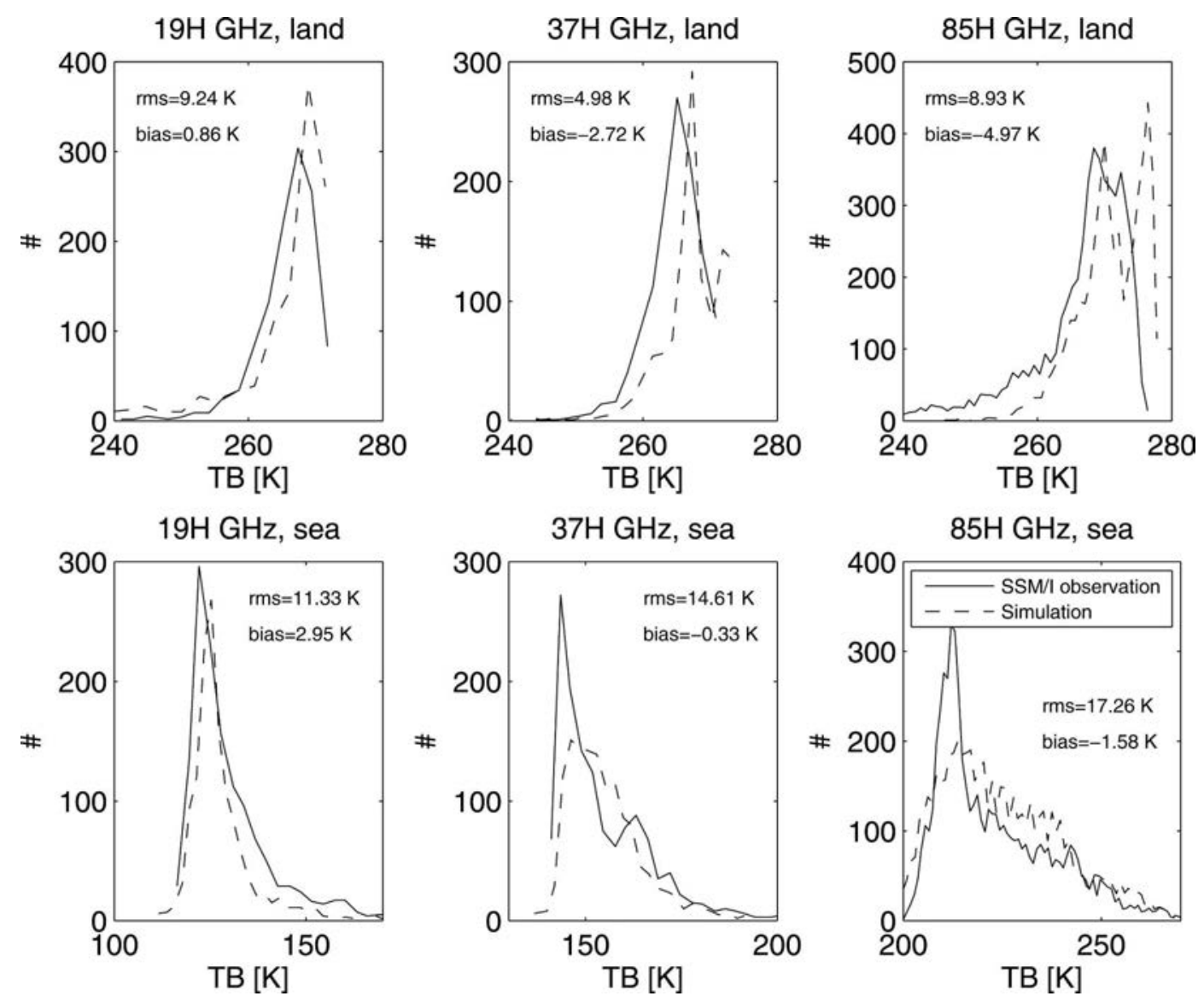

FIG. 3. Histograms of the observed (solid line) and simulated (dashed line) SSM/I TBs for selected channels. Data are separated into (top) land and (bottom) sea surfaces. The rms and the bias are indicated for each difference.

frequencies that are particularly sensitive to scattering by frozen particles.

\section{c. The observed and simulated TB distributions}

For a more quantitative comparison of the simulated and observed TBs, their statistical distributions (histograms) are compared in Fig. 3 for selected SSM/I channels. The data are divided according to the surface type (land and sea, coastal data being excluded). It is anticipated that the TB comparison would be less informative for the AMSU instruments because of their varying incidence angle. At all frequencies, the distributions of the TBs are significantly broader over ocean, because of the lower emissivity of the ocean surfaces. Hence, clouds cause a significant warming and therefore a widening of the TB distribution.

The $19-\mathrm{GHz}$ channels are highly responsive to surface emissivities, especially under clear sky conditions. A reasonable agreement of measured and simulated TB distributions at this frequency is found in Fig. 3.
Differences of TB (hereafter noted $\Delta \mathrm{TB}$ ) between observations and simulations are further separated into cloudy (flagged by the simulated clouds in Méso-NH) and clear pixels in Fig. 4. This confirms that the agreement is especially good under clear conditions and that surface emissivity estimates for land and sea are reliable, at least at low frequencies. Note that a nonnegligible dispersion of the $\Delta \mathrm{TBs}$ are expected due to a nonperfect coincidence between the atmospheric structures observed by the satellite and those of Méso-NH (on which the RT simulations are based). The $22-\mathrm{GHz}$ channel is sensitive to the total water vapor column over ocean. For this channel as well, good agreement is obtained.

Over ocean and land, an overestimation of the simulated TBs is apparent at 37 and $85 \mathrm{GHz}$. Emission from liquid clouds is significant at $37 \mathrm{GHz}$ and increases with the frequency. Low clouds simulated by the atmospheric model emit radiation therefore increasing the TBs as compared to a colder and cloud-free sea surface. 

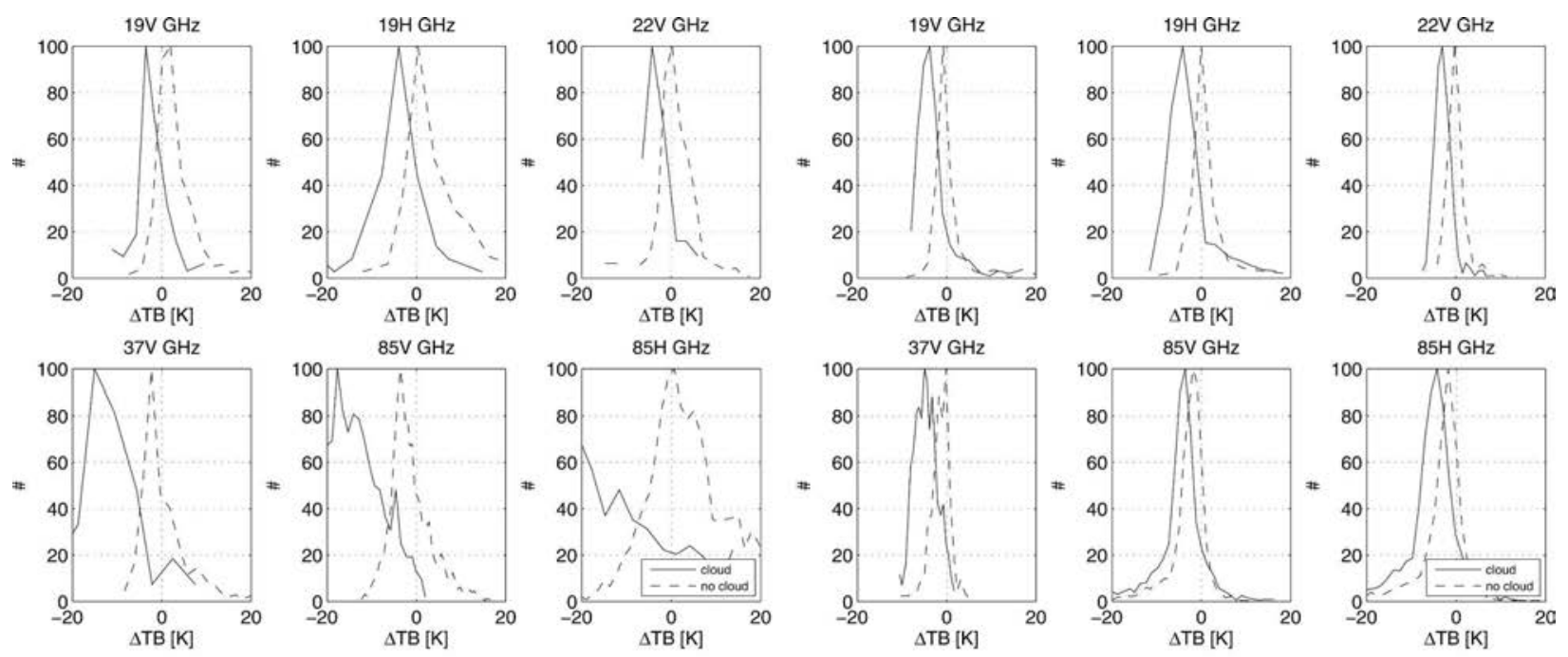

(a) Sea

(b) Land

FIG. 4. Normalized histograms of $\Delta$ TB for selected SSM/I channels for the Hoek case with data separated into (a) sea and (b) land surfaces. The dashed line corresponds to the difference (observation simulation) for pixels without clouds, the solid line for pixels with clouds.

For clear conditions (as flagged by Méso-NH; Fig. 4), the differences between simulations and observations do not show significant bias except at $85-\mathrm{GHz}$ vertical polarization. From Fig. 2, one can also notice that especially at $85 \mathrm{GHz}$, the impact of the cloud fields east of the U.K. coast seems overestimated as compared to the observations.

At $85 \mathrm{GHz}$ over land, a significant population of pixels has simulated TBs exceeding those of the observations (see Fig. 4). We checked that most of these pixels are located in central Germany/eastern France and southern Norway, where we already noticed (Fig. 2) too-high simulated TBs. The largest differences between observed and simulated TBs are located in regions where significant quantities of snow are present in the clouds. Other differences in regions where warm clouds are present have similar counterparts in the IR and it appears that these differences are due to expected slight mislocations of the cloud structure by the cloud model. To further evidence the critical importance of frozen particles in the simulations, histograms are presented at 89 and $150 \mathrm{GHz}$ separating the pixels according to the amount of snow total column, over land (Fig. 5). Small snow concentrations result in moderate $\Delta$ TBs centered close to zero. For a deeper column of snow the distributions shift toward larger $\Delta$ TBs. At $183.31 \pm 1$ the distributions are narrower and are centered on the same range of values. The explanation is that the channel weighting function peaks above the snow cloud and it is therefore not sensitive to the underlying layer of snow.

\section{d. Detailed analysis for a representative transect}

A closer look at the differences between simulated and observed TBs is presented along a transect of constant latitude of $50^{\circ}$ (Fig. 6). This cross section includes both liquid cloud and rain over the English Channel and over land and the presence of significant frozen quantities over Germany. The vertically integrated masses of the hydrometeors as calculated by Méso-NH are also displayed.

Over the Channel, west of $2^{\circ}$, it appears that the cloud and rain structure simulated by Méso-NH is translated westwards by $\sim 2^{\circ}$ with respect to the observations. This can be observed from both microwave channels (SSM/I and AMSU-B) and IR observations, although their overpass times differ slightly. It is also seen on Fig. 2, in the comparison between the observations and the simulations. Because of saturation effects, high frequencies (150-GHz channel and the IR observations) are less sensitive compared to the low frequency window channels. The spatial consistency between the microwave and the IR differences confirms that in this region, discrepancies between simulations and observations in the microwave are essentially related to a mislocation of the cloud structure, not to inaccurate RT simulation in the microwave.

East of $\sim 5^{\circ} \mathrm{E}$, there is an overestimation of the simu- 

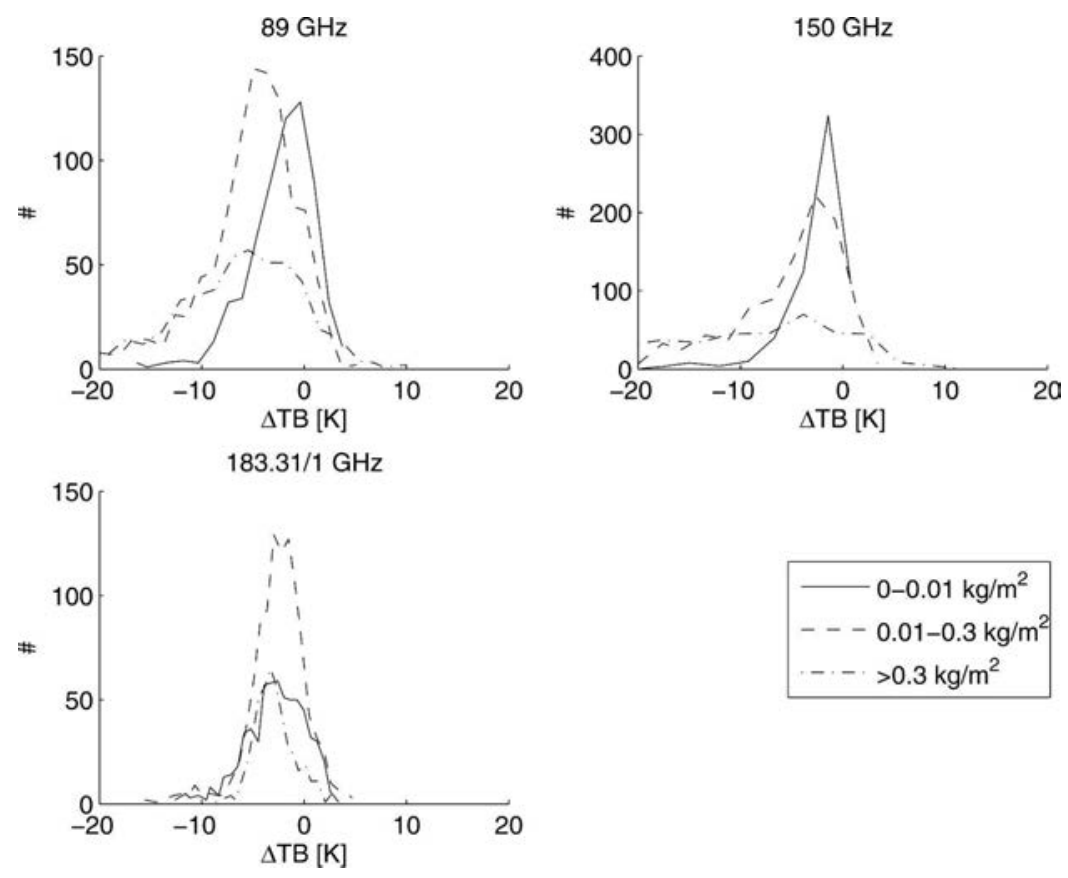

FIG. 5. Histogram of $\Delta$ TB for selected AMSU-B channels for the Hoek case over land for different ranges of snow total column.

lated microwave TBs that increases strongly with frequency in the window channels. The frequency and angular dependencies of the discrepancy is consistent with an underestimation of the scattering efficiencies of frozen particles. Here, TB errors are quite low (of the order of $2 \mathrm{~K}$ ) at $19 \mathrm{GHz}$ while they reach $40 \mathrm{~K}$ at 85 $\mathrm{GHz}$ as observed by SSM/I at a constant $53^{\circ}$ incidence. The discrepancy observed at $89 \mathrm{GHz}$ with AMSU-B is more limited: with close to nadir incidence in this area (from $15^{\circ}$ at $7^{\circ} \mathrm{E}$ to $1^{\circ}$ at $12^{\circ} \mathrm{E}$ ), AMSU-B TB depression due to scattering are expected to be weaker. At $150 \mathrm{GHz}$, the difference observed by AMSU-B is larger than at $89 \mathrm{GHz}$, as expected. The stronger the water vapor absorption in the $183 \mathrm{GHz}$ channels, the smaller the discrepancy: first, the TBs being already rather cold in the most absorbing channels, the effect of scattering by the frozen particles is less obvious; second, the frozen particles can be at least partly located below the peak of the weighting function and will thus have a more limited impact. On the thermal IR signal, no significant difference is found in this region meaning that the cloud top temperature is correctly estimated by Méso-NH.

\section{Sensitivity of the microwave simulations to the hydrometeor characteristics}

Comparisons between microwave simulations and observations show a satisfactory agreement, except in some extended areas where frozen particles are encountered. In these regions, observations let us conclude that standard RT calculations underestimate dramatically the scattering by snow particles. This behavior is found for the five midlatitude cases that have been analyzed so far (Crewell et al. 2005; Prigent et al. 2005c) although only the most illustrative case (the present Hoek case) is detailed here.

For the five cases, TB depressions are unambiguously related to a misrepresentation of the scattering properties of an ice particle type that is not abundant in the tropical cases examined by Wiedner et al. (2004). Whereas the tropical cases correspond to vigorous convective systems (a cyclone and a convergence line over Brazil) dominated by large frozen and riming scatterers such as the graupel, the more stratiform midlatitude cases are characterized by diluted frozen particle concentrations that are composed of snow crystals and aggregates. Several explanations can be put forward to interpret this discrepancy between the simulations and the observations:

- the ice particles, essentially irregular or assemblage of snow crystals, are not correctly taken into account in the RT model in terms of effective size, shape, and refractive properties;

- the amount of frozen particles produced by Méso$\mathrm{NH}$ is underestimated for midlatitude situations.

The physical parameters describing snow particles or the amount of predicted snow in the clouds are subject 

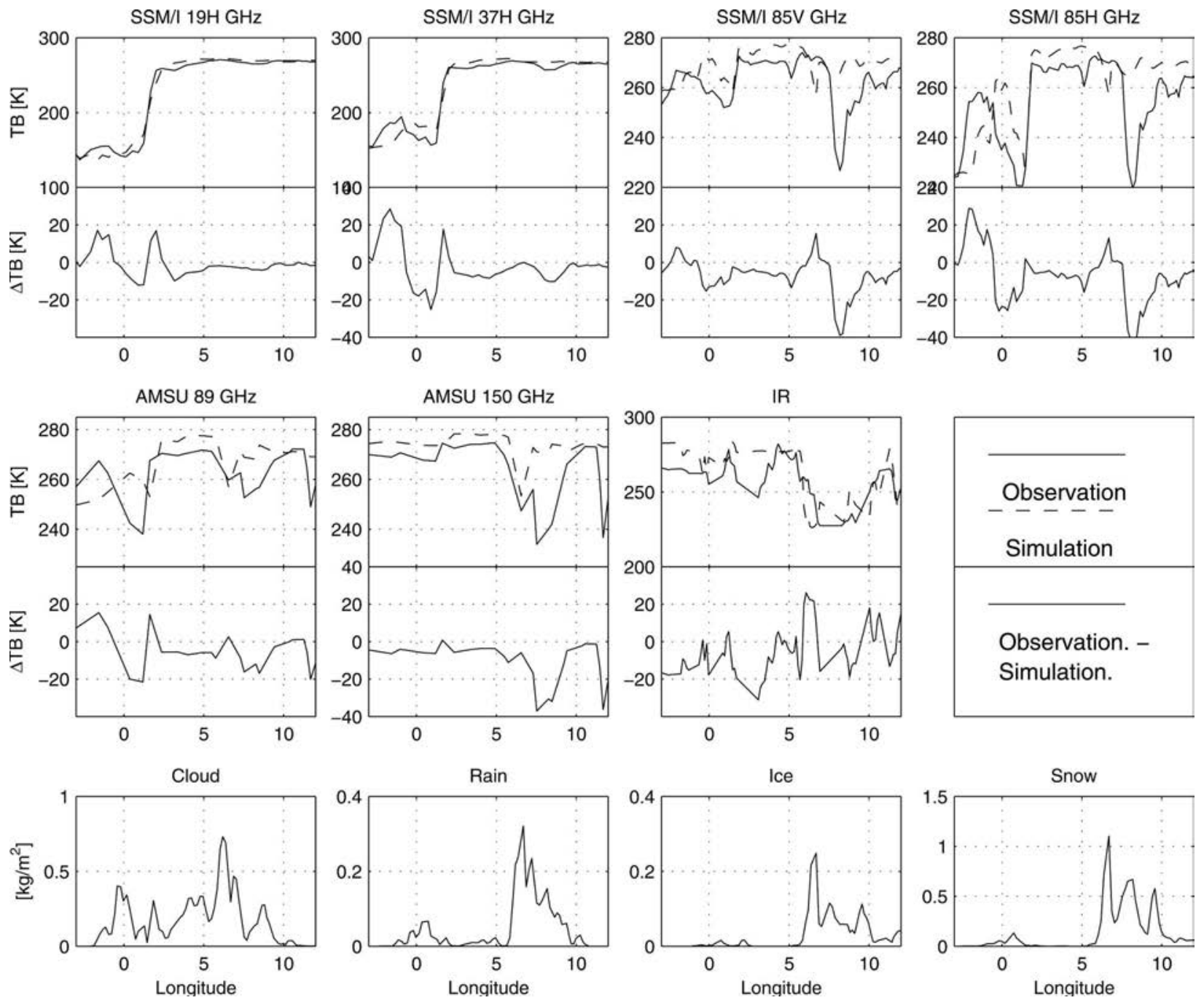

FIG. 6. Transects at $50^{\circ}$ for the Hoek case. Simulations and observations of TBs at selected SSM/I and AMSU-B frequencies are shown as well as their difference. In the lowest row, hydrometeor integrated columns as simulated by Méso-NH are represented.

to uncertainties, which originate from the microphysical scheme of the mesoscale model Méso-NH or which depend on a given interpretation of these particles in terms of radiative scattering efficiency. In this section, an analysis of the possible sources of uncertainty is attempted.

\section{a. Particle size and density}

For each layer and each hydrometeor category, Méso-NH provides the mixing ratio $r_{x}$ and the size distribution of the maximum dimension of the particle [Eq. (2) and Table 1]. The intrinsic mass of the particles is specified $\left(m=a D^{b}\right)$ but the shape of the particles or in other words their volume and density, which are not explicitly needed in the microphysical scheme but which are indeed crucial parameters affecting the scat- tering properties, are free parameters. Liquid drops are spheres $(b=3$; Table 1$)$. Graupel and small ice crystals are not strictly spheres $(b=2.8$ and $b=2.5$, respectively), but are approximated so in the RT code because there is no real justification for a more complicated treatment. With $b=1.9$, snow particles are the most challenging particles because they are clearly not spherical. In this work, two shape approximations are tested: the sphere case and the randomly oriented oblate spheroids. The oblate spheroid shape for snow is favored by polarimetric radar studies (Vivekanandan et al. 1994; Ryzhkov et al. 1998). Figure 7 displays the particle size distributions, as given by Méso-NH for three mixing ratios. For comparison purpose, the equivalent size distributions used in SkofronickJackson et al. (2002) are also drawn. It is emphasized 

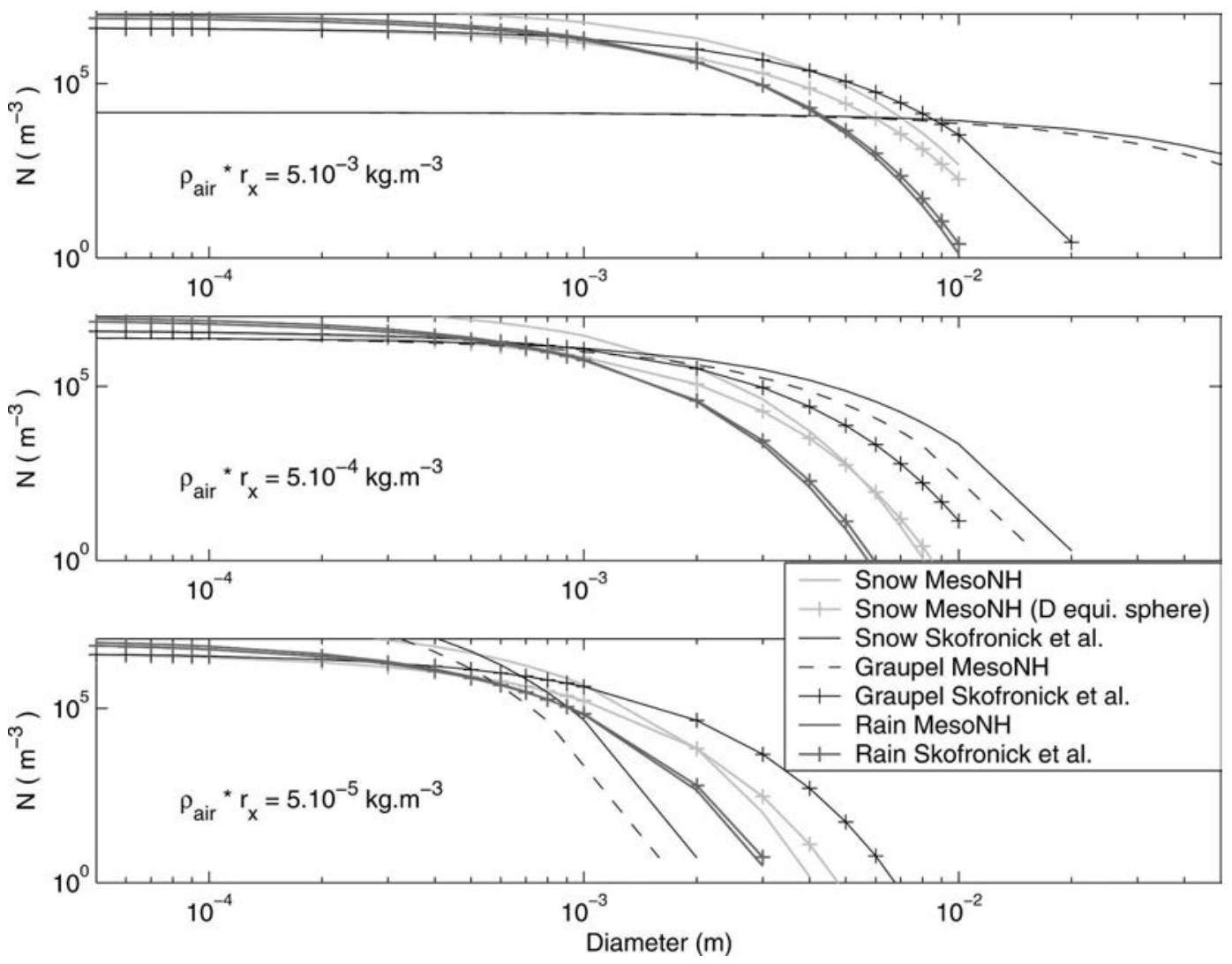

FIG. 7. Particle size distributions of the hydrometeors following different assumptions (see text for more details).

that in the Méso-NH scheme, the diameter $D$ corresponds actually to the largest dimension of the (falling) particle and not to a melted diameter of the drop of same mass. Two Méso-NH size distributions are shown for snow. The first one considers $D$ as the largest dimension of the particle, the second one considers $D$ as the diameter of the sphere of equivalent volume, the particles being oblate spheroids with an aspect ratio of 2 (the largest axis being twice the smaller one).

The largest variability in Fig. 7 is observed for the snow size distributions (note that the mass concentration of $5.10^{-3} \mathrm{~kg} \mathrm{~m}^{-3}$ is not realistic for snow and is just shown for comparison with the others). In the tropical cases explored by Wiedner et al. (2004), the graupel mixing ratios were usually high compared to those of snow and microwave scattering was dominated by the graupel. In midlatitude cloud systems, snow mixing ratios in precipitating clouds are comparable or sometimes larger than the graupel ones and the accurate treatment of the snow in the RT simulations is required.

The particle density is a critical parameter that determines the dielectric properties, and as a consequence the scattering efficiency of the particles. As introduced above, the density of snow particles is an opened microphysical parameter in Méso-NH until a hypothesis is made on the shape of the particle. Figure 8 shows the density of the graupel and of the snow particles as calculated with different assumptions.

The graupel are rimed particles for which it is reasonable to assume a spherical shape with diameter and mass given by Méso-NH (see Table 1). Their density is below $0.3 \mathrm{~g} \mathrm{~cm}^{-3}$, lower than the values used by Burns et al. (1997; $\left.0.6 \mathrm{~g} \mathrm{~cm}^{-3}\right)$ and Skofronick-Jackson et al. $\left(2002 ; 0.4 \mathrm{~g} \mathrm{~cm}^{-3}\right)$. The snow density is calculated considering spheres and oblate spheroids with an aspect ratio of 2. The density modeled by Matrosov et al. (1996) is also presented (density $=0.07 D^{-1} \mathrm{~g} \mathrm{~cm}^{-3}$ ) with $D$ the equivolume particle diameter (the sphere and the spheroid with aspect ratio of 2 are shown). Regardless of the model, the snow density falls abruptly from the ice density $\left(0.917 \mathrm{~g} \mathrm{~cm}^{-3}\right)$ to very low densities, well below the $0.1 \mathrm{~g} \mathrm{~cm}^{-3}$ density value that is often selected (e.g., Burns et al. 1997; SkofronickJackson et al. 2002).

For the snow, another approach is suggested by Liu (2004). By analyzing accurate discrete dipole approxi- 


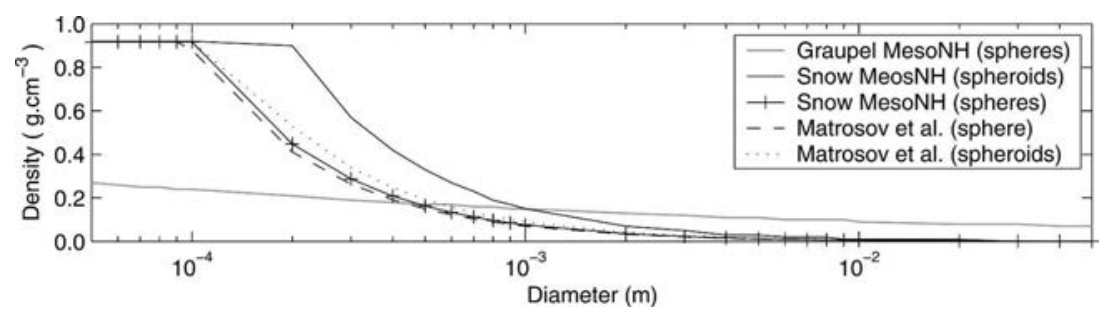

Fig. 8. Calculation of the particle density assuming different particle size distributions and shapes (spheres or oblate spheroids with an aspect ratio of 2). See text for more details.

mation (DDA) modeling, Liu observes that snow has scattering and absorption properties between those of a solid ice equal-mass sphere of diameter $D_{0}$ and a ice-air mixed sphere with a diameter equal to the maximum dimension of the particle $D_{\max }$. For each frequency and particle shape, a softness parameter [SP $=\left(D-D_{0}\right) /$ $\left.\left(D_{\max }-D_{0}\right)\right]$ is derived that gives the diameter of the best-fit equal-mass sphere. For each particle shape, this is actually equivalent to use a frequency dependent effective density along with modified diameters.

\section{b. Refractive index of the hydrometeors}

The refractive index for liquid water is rather well established (although measurements are very limited at high frequencies and low temperatures) and is taken from Manabe et al. (1987) for rain and cloud droplets. Mätzler (2006) recently reviewed the works performed on the ice and snow refractive index at microwave and millimeter wave frequencies. This study includes among others the results from Jiang and $\mathrm{Wu}$ (2004). The model preferred by Mätzler (2006) and by Jiang and $\mathrm{Wu}$ (2004) is compared to the Warren (1984) parameterization (used in Wiedner et al. 2004). Differences between models are limited, although they are slightly larger at lower frequencies for the real part of the index. For the imaginary part, the new model predicts a frequency dependence, whereas Warren (1984) considered it fixed "over a large region of the microwave and radiowave spectrum."

Snow and graupel are considered heterogeneous media, made of ice and air. The permittivity can then be calculated from the permittivity of ice, knowing the density of the particles. A large number of mixing formulas are available in the literature. The most common one is the Maxwell-Garnett formula that gives the effective dielectric constant of a mixture as a function of the dielectric constants of the host material and inclusions. For snow and graupel, the host is the air and the inclusion is the ice. Other mixing formulas can be found in the literature and several have been tested (Ulaby et al. 1986; Matrosov et al. 1996; Mätzler 2006) for snow for different densities. For a given snow density, the differences essentially come from the modeling of the ice permittivity. The tested mixing formulas give very similar results, being all derived from the same theory. In the following, we will use the Maxwell-Garnett formula itself, with the Mätzler (2006) ice model.

The impact of potential snow wetness has also been tested. The wetness percentage $(W)$ of SkofronickJackson et al. (2002) is adopted: it predicts the increase of wetness with temperature $[W(\%)=0$ for $T<258.15$ $\mathrm{K} ; W(\%)=T-258.15$ for $T<258.15 \mathrm{~K} ; W(\%)=15$ for $T>273.15 \mathrm{~K}$ ]. The percentage of air, ice, and water are adjusted by converting air into water following the above relations. The Maxwell-Garnett mixing formula is used twice, first for the mixing of ice in an air matrix and second for the mixing of water in the air-ice matrix. The wetness has a strong influence on the refractive index (not shown) that will translate in stronger absorption.

It is to be stressed that these refractive index estimates are based on a very limited number of experiments (Mätzler 2006) at very few frequencies, and under laboratory conditions where the ice/snow properties can significantly differ from those in the cloud environment.

\section{c. Frozen particle concentration}

To assess the range of variability related to the mesoscale cloud model, simulations from the Méso-NH and the German Lokal-Modell are compared. This comparison does not intent to evaluate one model with respect to the other, but to point out the differences in the simulated frozen quantities depending on the microphysical parameterization, and thus to have an idea of the uncertainty of these quantities.

The Lokal-Modell (LM; Steppeler et al. 2003) of the German Meteorological Service (DWD) is a fully compressible nonhydrostatic model, currently in operation with a horizontal resolution of $7 \mathrm{~km}$. In this study, model integrations are performed on a finer grid with $2.8 \mathrm{~km}$ resolution, which covers $440 \mathrm{~km} \times 440 \mathrm{~km}$ cen- 

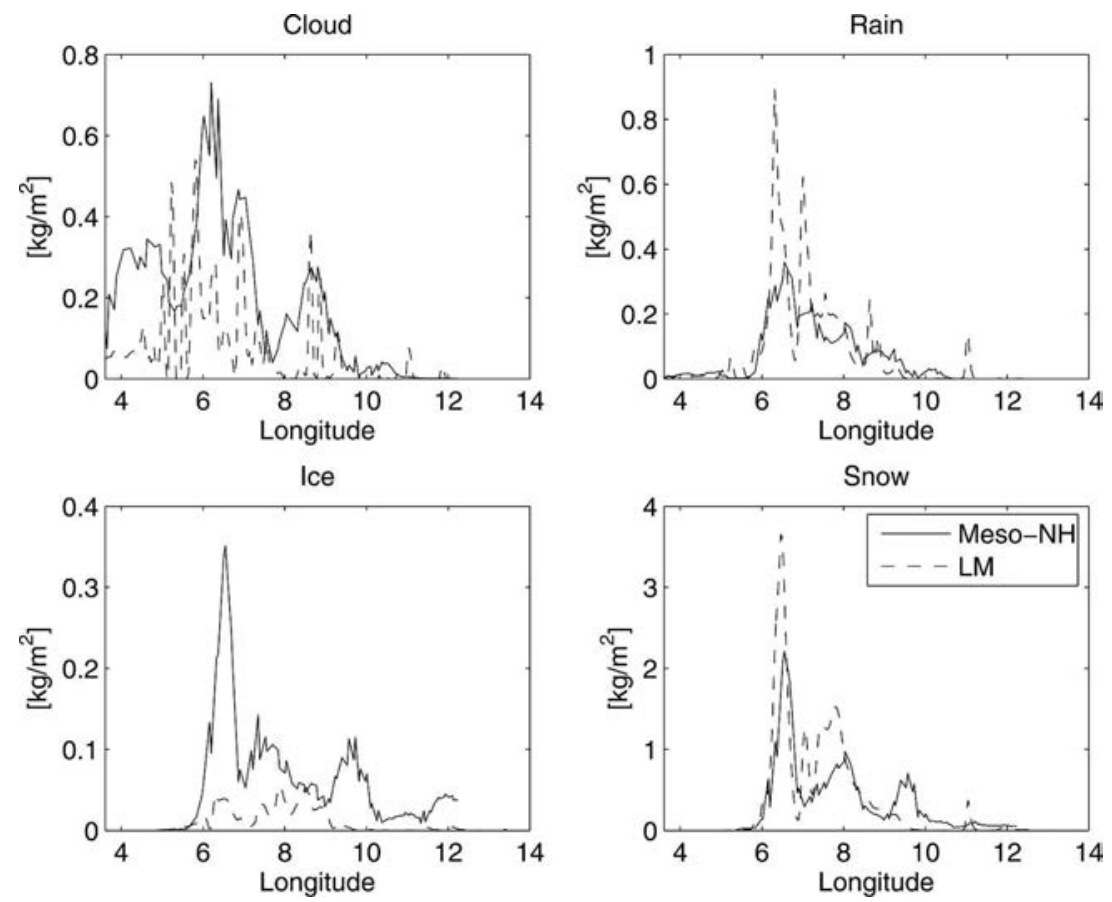

FIG. 9. Hydrometeor quantities as simulated by Méso-NH and LM for the $50^{\circ}$ latitude transect of the Hoek case.

tered over the Netherlands. The configuration of LM has been adapted accordingly: at first, parameterized moist convection is switched off since it is assumed that most features of deep convection are resolved. Second, the numerical treatment is improved to ensure accurate and positive definite advection of hydrometeors and to reduce numerical diffusion. A two-level time integration scheme based on a Runga-Kutta method (Wicker and Skamarock 1998) is applied and advection of hydrometeors is calculated by a semi-Lagrangian algorithm. Prognostic model variables are the same as for Méso-NH and are vertically discretized on 35 hybrid levels. The LM comprises a state-of-the-art package of parameterizations of all nonresolved processes, for example, for subgrid-scale turbulence, radiative fluxes, and a one moment bulk scheme. More details are available in Doms and Schättler (1999).

The spatial structures of the clouds generated by the two simulations are similar. However, significantly larger frozen quantities are generated by the German mesoscale scheme (see Fig. 9), giving an idea of the uncertainty to be expected from the cloud simulations.

\section{d. TB simulations with different assumptions}

Our objective in this section is to analyze the sensitivity of the radiative transfer simulations to the different hypothesis, in the presence of significant amount of scattering particles and to recommend the most realistic set of scattering parameters. Our selection criteria are based on simulations at 89 and $150 \mathrm{GHz}$ because these frequencies are the most sensitive to scattering by hydrometeors as shown above. As previously discussed, the main discrepancies between observations and simulations occur in regions where snow dominates in the atmospheric column. Our analysis of tropical situations showed that good agreements were obtained in areas where graupel contents were much more important than snow ones (Wiedner et al. 2004). Thus, we will essentially test the influence of the snow parameters on the radiative transfer. We concentrate here on the results along a representative transect for the Hoek case (Figs. 6 and 9).

Figure 10 shows simulations at 89,150 , and $89-150$ $\mathrm{GHz}$ for this transect for various hypotheses, compared to the AMSU-B observations for the same locations. The observations being performed at different angles, the simulations will be presented for two incidence angles $\left(8^{\circ}\right.$ and $\left.19^{\circ}\right)$.

The first simulation (black curves) corresponds to the initially selected parameters for snow. The dielectric properties are calculated from the Maxwell-Garnet mixing formula, using Mätzler (2006). The particles are spheres and for each particle type, the nominal size distribution of Méso-NH is used. There is almost no scattering simulated, both at 89 and $150 \mathrm{GHz}$. 

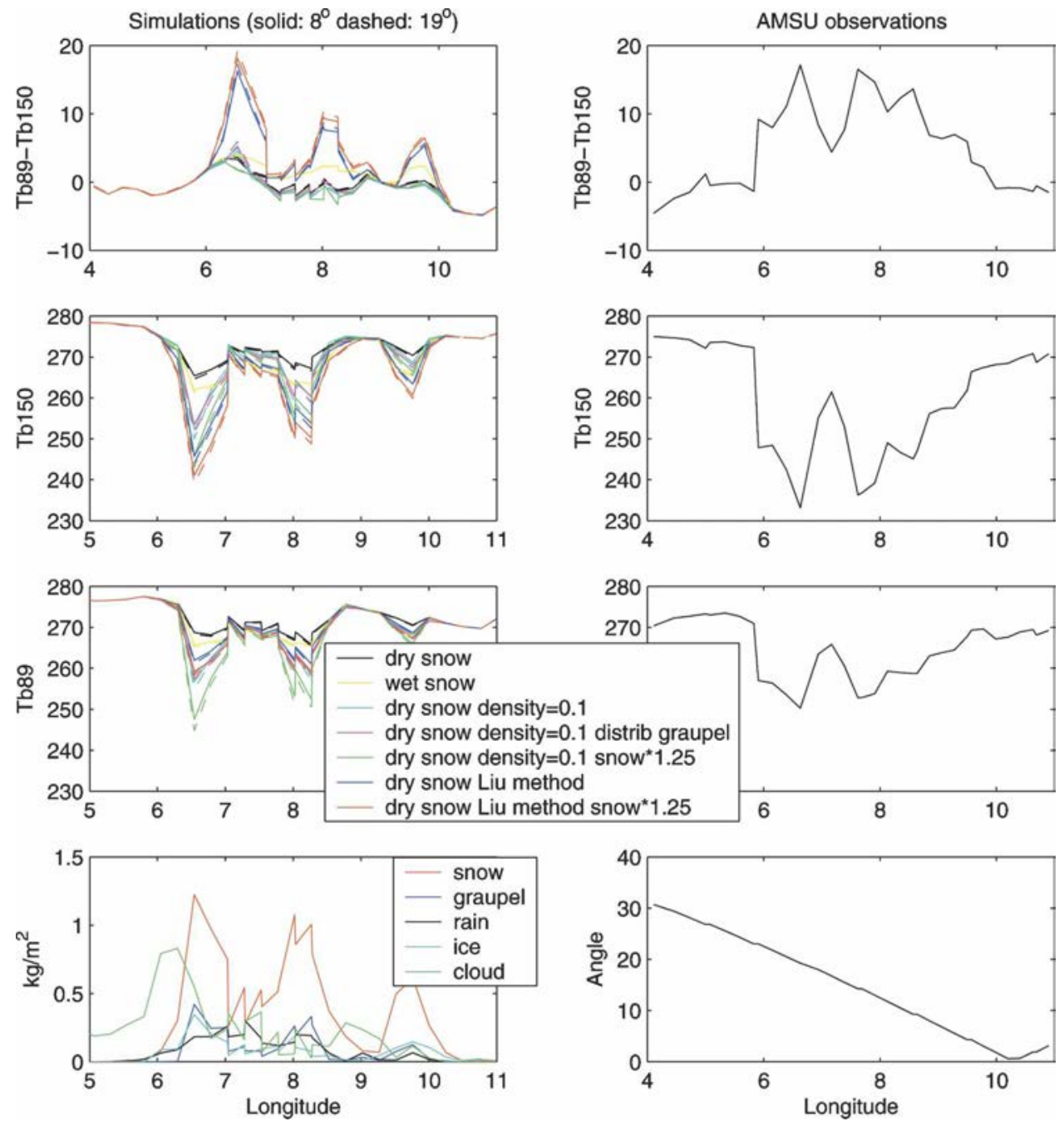

FIG. 10. Brightness temperatures at 89,150 , and $89-150 \mathrm{GHz}$ for a transect at a constant latitude of $50^{\circ}$ for the Hoek case. (right) The AMSU-B observations and (bottom) the corresponding incidence angle. (left) The simulations under different assumptions for the snow treatment, presented for two incidence angles $\left(8^{\circ}\right.$ and $\left.19^{\circ}\right)$, (bottom) along with the hydrometeor integrated quantities. See text for more details.

Multiplying the snow content by 1.5 or by 0.5 in each layer does not change the result by more than $1 \mathrm{~K}$ along the transect. Switching from the Maxwell-Garnet mixing formula to the Ulaby et al. (1986) one for the snow dielectric properties does not improve the results (not shown). Considering snow, with a wetness degree depending on the temperature of the layer, the TBs decrease by a few kelvin (see the yellow curves in Fig. 10). Changing the snow size distribution to the one used for the graupel does not change the TBs much either (not shown). All these experiments lead to the conclusion that the selected snow parameters are such that even with a column-integrated content higher than $1 \mathrm{~kg} \mathrm{~m}^{-2}$, the snow particles are transparent to the microwaves. The snow particle sizes that are likely to scatter radia- tion at 89 and $150 \mathrm{GHz}$ have a very low density (see Fig. 8). Hence, it seems that probably the too-low density of the largest flakes is responsible for the poor dielectric properties that result in only very weak scattering.

Calculations are then performed, assuming that the snow particles are randomly oriented oblate spheroids (not shown). Slightly more scattering is produced, but a closer examination of the results shows that it is not essentially due to the change in particle shape but to its impact on the snow density and as a consequence on the snow dielectric properties: when changing from spheres to spheroids with the same maximum diameter $D$, the volume of this particle decreases for the same mass ( $m={ }_{a} D^{b}$ in Méso-NH) and as a consequence its density increases. 
A density of $0.1 \mathrm{~g} \mathrm{~cm}^{-3}$ is then applied to the snow particles, a value that is often selected for snow (light blue curves in Fig. 10). For consistency purposes, a minimum threshold of $0.1 \mathrm{~g} \mathrm{~cm}^{-3}$ is also applied to the graupel density. Changing the density of snow leads to a significant decrease of the TBs. Setting the graupel density to $0.4 \mathrm{~g} \mathrm{~cm}^{-3}$ regardless of the graupel particle size yields TBs that are very low, much lower than the AMSU-B observed values for this case, confirming our previous study of tropical cyclones (Wiedner et al. 2004). These results suggest that a constant density of $0.1 \mathrm{~g} \mathrm{~cm}^{-3}$ for the density of snow is a good compromise to describe the snow density, as this clearly improves the scattering by large snow particles. The density of graupel is kept at its initial value calculated from Méso$\mathrm{NH}$ assumptions but with a minimum of $0.1 \mathrm{~g} \mathrm{~cm}^{-3}$ : this is consistent with the physical sense that for a given particle size, graupel is growing denser than snow.

Under these assumptions (light blue curves in Fig. 10), the magnitude of the TBs depression related to the scattering is of the same order, for both 85 and 150 GHz. Examination of Fig. 2 shows that the observed scattering at $150 \mathrm{GHz}$ is significantly larger than at 85 $\mathrm{GHz}$, and the simulations should reproduce this spectral dependence. The purple curves in Fig. 10 represent RT simulations with the size distribution of snow taken identical to the graupel one, thus assuming fewer large particles and more abundant smaller ones. The simulation shows a slightly improved frequency gradient but still much weaker than the observed one.

The sensitivity to the snow content is then analyzed. The German LM model has been shown to predict more frozen quantities than Méso-NH so additional RT simulations are performed, multiplying the snow content by 1.25 in each atmospheric layer (the density of snow is $0.1 \mathrm{~g} \mathrm{~cm}^{-3}$ and the original snow size distribution is reset). The TBs are significantly depressed for both frequencies (green curves in Fig. 10).

Finally, the method developed by Liu (2004) is also tested, using the averaged softness parameters of 0.33 and 0.27 for 89 and $150 \mathrm{GHz}$, respectively, as suggested in Liu (2004; dark blue curves). The results are very encouraging: not only the magnitude of the scattering is close to the observations, but the frequency gradient also agrees with the measurements. The softness parameters are frequency sensitive and have been tuned by Liu (2004) to obtain an optimal agreement with the discrete dipole approximation calculations. This solution is selected as the optimum one. In the last simulation (red curves), the method by Liu is also adopted, but with a multiplication factor of 1.25 on the snow quantities in Méso-NH. As compared to the previous simulation, the improvement is not significant.
The complete Méso-NH field for the Hoek case is then simulated for AMSU and SSM/I conditions using the initial Méso-NH outputs and assumptions for all quantities, along with the Liu (2004) softness parameter for snow. Figure 11 shows the results for the AMSU-B channel at 150,89 , and $89-150 \mathrm{GHz}$, as compared to the observations and to the previous original simulations. The new simulations show enhanced scattering (lower TBs) at $150 \mathrm{GHz}$ in the convective region where snow is present. It also shows an improved simulation of the frequency gradient $(89-150 \mathrm{GHz})$ as compared to the satellite measurements. Similar simulations have been performed for the four other cases and for example a light precipitation event over the Rhine River, 10 February 2000, is shown. The AMSU instrument at 150 $\mathrm{GHz}$ observes significant scattering over east France and Germany. With the original snow parameterization, very limited scattering is simulated, whereas the new simulations show more scattering, closer to the observed values. One can notice that the surface emission over the snow-covered Alps is very well reproduced by our simulations.

For the five cases, the satellite-observed TBs have been compared to simulations with the old and new treatments of snow in the RT, with consistent better agreement with the new simulations. There are still differences between the simulated and the observed fields over cloud structures at these high frequencies, as expected due to their large sensitive to the detailed microphysics of the hydrometeors, but a better agreement is systematically observed for midlatitude cases when changes are applied to the snow treatment.

\section{Conclusions}

Microwave radiative transfer simulations have been performed using outputs from the Méso-NH mesoscale model simulations for midlatitude meteorological systems. The results from a representative case over western Europe are described in details in this paper and compared to the corresponding microwave observations from two microwave instruments, SSM/I and AMSU, between 19 and $190 \mathrm{GHz}$. In addition, IR simulations at $11 \mu \mathrm{m}$ are performed for the same meteorological situation and compared to the coincident Meteosat image.

The radiative transfer code ATM has been adapted to benefit from a detailed description of the hydrometeor properties as simulated by the Méso-NH microphysical scheme. The interpretation of some unspecified characteristics of the hydrometeor fields (here mostly composed of snow particles) is the focus of the study. 

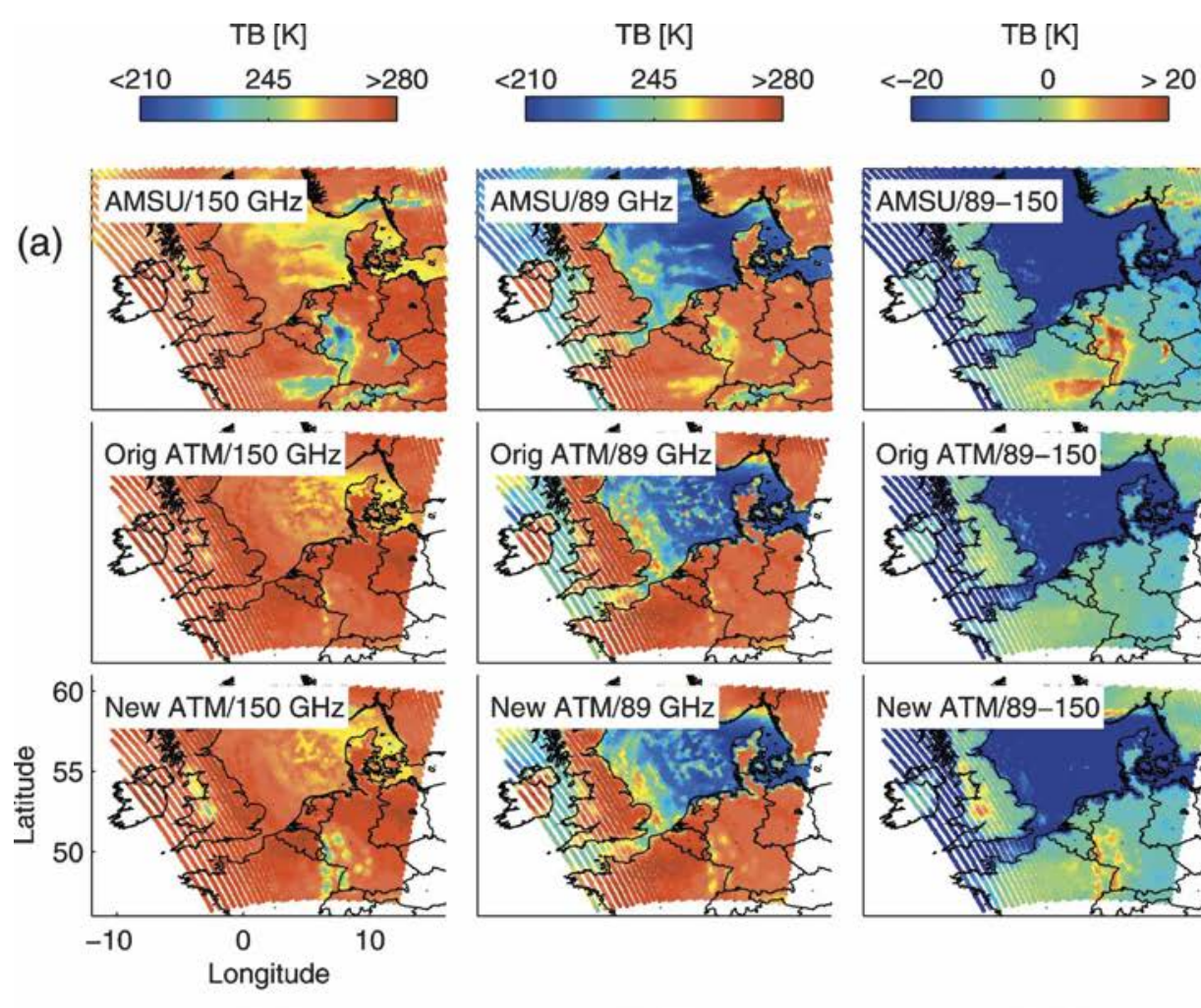

\section{(a)}
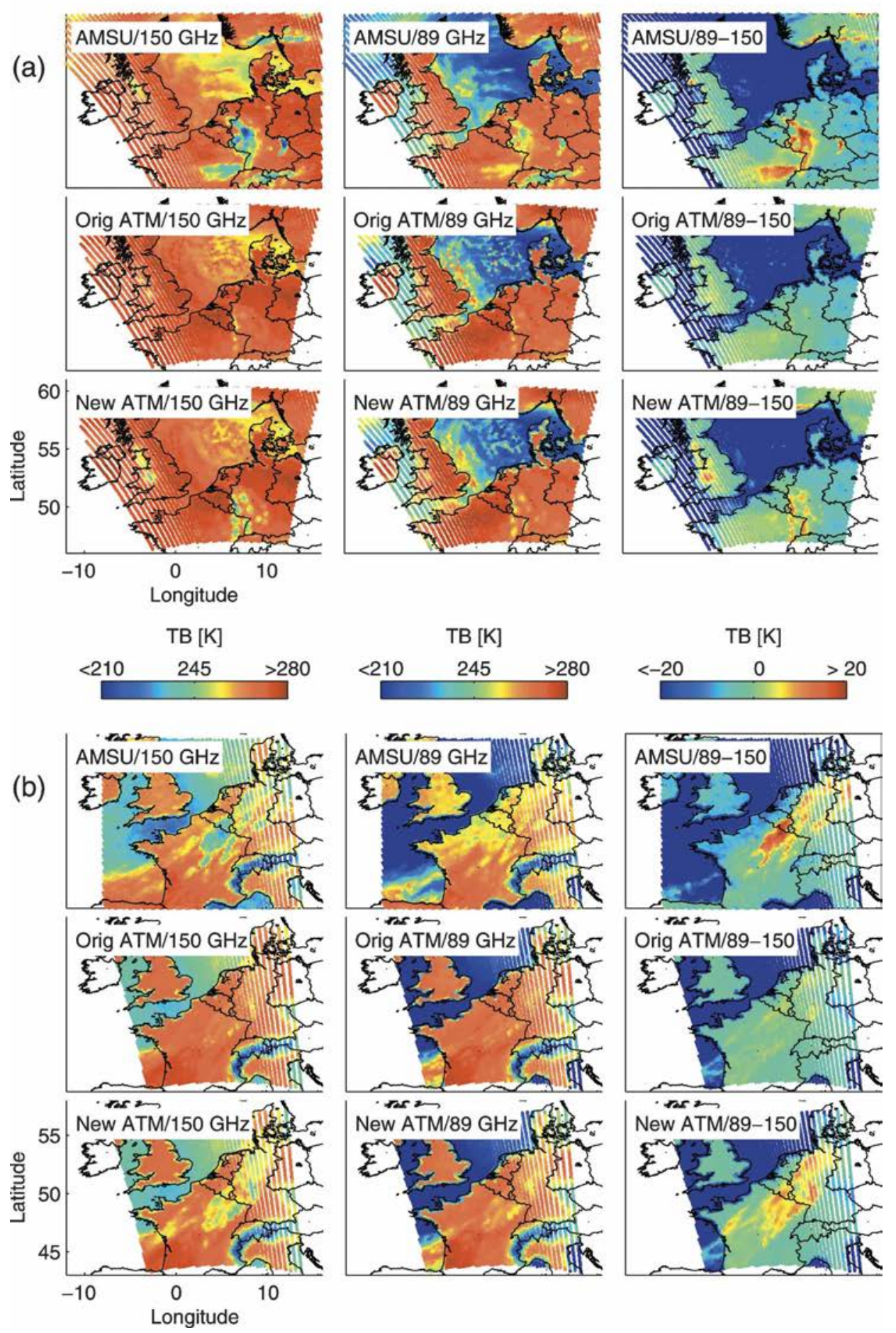

FIG. 11. For two cases [(a) Hoek and (b) Rhine]: (top) AMSU-B observations, as compared to corresponding simulations with the (middle) original assumptions for the treatment of snow, and (bottom) assumptions for snow. Results are presented at (left) 150, (middle) 89, and (right) 89-150 $\mathrm{GHz}$. 
Comparing simulations and observations over a large range of frequencies is a very challenging but fruitful experience. Each frequency is sensitive to a large set of atmospheric and surface parameters, imposing very strong constraints on the quality of both the Méso-NH simulations and the RT scheme. SSM/I low frequencies are more sensitive to the lower part of the atmospheric column, including the surface contribution. In contrast, the SSM/I channel at $85 \mathrm{GHz}$ and the AMSU-B window channel at 89 and $150 \mathrm{GHz}$ are responsive to scattering by frozen particles. The use of the thermal IR channel helps the interpretation of the microwave simulation/observations comparisons.

An overall agreement is obtained between the simulated and the observed TBs in the microwave and in the thermal IR. The large scale dynamical structure of the cloud system is well captured by Méso-NH, with, as expected, local differences in the small-scale features. Comparisons between microwave simulations and observations show satisfactory agreement, except in the areas with frozen particles. This is confirmed by the four other midlatitude cases that we also analyzed. The intriguing fact is the lack of scattering by complex shape frozen particles in the microwave. This can be related to two main causes: 1 ) the frozen particle scattering properties are not correctly interpreted in the radiative transfer code, 2) there is a lack of frozen particles in Méso-NH for these midlatitude cases, although good agreements were obtained for tropical cases (Wiedner et al. 2004). Radiative transfer sensitivity tests have been performed and comparisons with the German mesoscale cloud model (LM) have also been examined. From our analysis, it seems that the discrepancy is essentially related to the snow parameterization in the radiative transfer code as interpreted from Méso-NH. For instance, decreasing the density of snow particles with size as intuitively suggested by microphysical schemes, leads to an electrical permittivity of snow that is too low to efficiently scatter upwelling radiations even for large particles. Liu (2004) derived a frequency dependent effective density for snow in order to minimize scattering calculation differences between the discrete dipole approximation and the Mie theory. Using this frequency dependent density for snow, a good agreement between simulations and observations is obtained both at 89 and $150 \mathrm{GHz}$, even in the areas with significant frozen particles.

These comparisons between RT simulations and satellite observations over a large frequency range are a very promising way to evaluate the cloud fields of mesoscale models at the large scales. During welldocumented experiments, the assessment of the detailed internal structure of mixed-phase clouds with (polarimetric) radar is very valuable at small scale. However, at large scales, the model-to-satellite approach based on passive microwave observations is particularly powerful for systematically and rapidly evaluating the liquid and ice amounts predicted by the cloud scheme of mesoscale models.

A dataset of five midlatitude cases has been created, containing the detailed microphysical information to perform accurate radiance simulations and a radiative transfer code is fully interfaced with it. This is the ideal tool to analyze the sensitivity of a specific frequency range to cloud characteristics and to develop rain and cloud inversion algorithms for the next generation of satellite borne instruments. This methodology is now being used to estimate the potential of millimeter and submillimeter frequencies for rain, precipitating ice, and cloud characterization. For a high temporal sampling of precipitation and extreme weather events, observations from geostationary orbits are necessary and this frequency range is explored to provide the adequate spatial resolution from these very remote orbits.

Acknowledgments. We thank an anonymous reviewer and Guosheng Liu for very constructive comments on this paper. Suggestions from Guosheng Liu were particularly helpful. This study has been supported by ESA under Contract 18054/04/NL/FF (Study of the potential of sub-millimeter observations for precipitation retrieval) and EUMETSAT under Contract EUM/CO/04/1311/KJG (Simulation study of precipitation clouds from geostationary orbits with passive microwaves). We acknowledge the support of CLS (Toulouse) in this project. We wish to thank Ulf Klein from ESA for his constructive comments during this study. Computer resources were allocated by IDRIS. AMSU data come from the NOAA Satellite Active Archive. Meteosat observations are copyright 2003 EUMETSAT.

\section{REFERENCES}

Bauer, P., P. Lopez, A. Benedetti, D. Salmond, and E. Moreau, 2005: Implementation of a 1D+4D-Var assimilation of precipitation affected microwave radiances at ECMWF. Part I: ID-Var. Quart. J. Roy. Meteor. Soc., 131, 2277-2306.

Buehler, S., cited 2005: Cloud ice water submillimeter imaging radiometer. Response to ESA call for earth explorer missions, University of Bremen, $20 \mathrm{pp}$. [Available online at http://www.sat.uni-bremen.de/projects/ciwsir/.]

Burns, B. A., X. Wu, and G. R. Diak, 1997: Effects of precipitation and cloud ice on brightness temperatures in AMSU moisture channels. IEEE Trans. Geosci. Remote Sens., 35, 1429-1437.

Caniaux, G., J.-L. Redelsperger, and J.-P. Lafore, 1994: A numerical study of the stratiform region of a fast-moving squall line. 
Part I: General description and water and heat budgets. $J$. Atmos. Sci., 51, 2046-2074.

Chaboureau, J.-P., J.-P. Cammas, P. J. Mascart, J.-P. Pinty, C. Claud, R. Roca, and J.-J. Morcrette, 2000: Evaluation of a cloud system life-cycle simulated by Meso-NH during FASTEX using METEOSAT radiances and TOVS-3I cloud retrievals. Quart. J. Roy. Meteor. Soc., 126, 1735-1750.

,,,---- —, and J.-P. Lafore, 2002: Mesoscale model cloud scheme assessment using satellite observations. J. Geophys. Res., 107, 4301, doi:10.1029/2001JD000714.

Chevallier, F., P. Bauer, G. Kelly, C. Jakob, and T. McNally, 2001: Model clouds over oceans as seen from space: Comparison with HIRS/2 and MSU radiances. J. Climate, 14, 4216-4229.

Crewell, S., and Coauthors, 2005: Simulation study of precipitating clouds from geostationary orbits with passive microwaves. EUMETSAT Contract Rep. EUM/CO/04/1311/KJG (final report), $90 \mathrm{pp}$.

Doms, G., and U. Schättler, 1999: The nonhydrostatic limitedarea model LM (Lokal-Modell) of DWD. Part I: Scientific documentation. DWD Rep., 112 pp.

Evans, K. F., and G. L. Stephens, 1995: Microwave radiative transfer through clouds composed of realistically shaped ice crystals. Part I: Single scattering properties. J. Atmos. Sci., 52, 2041-2057.

— S. J. Walter, A. J. Heymsfield, and G. M. McFarquhar, 2002: Submillimeter-wave cloud ice radiometer: Simulations of retrieval algorithm performance. J. Geophys. Res., 107, 4028, doi:10.1029/2001JD000709.

_ J. R. Wang, P. E. Racette, G. Heymsfield, and L. Li, 2005: Ice cloud retrievals and analysis with the compact scanning submillimeter imaging radiometer and the cloud radar system during CRYSTAL-FACE. J. Appl. Meteor., 44, 839-859.

Eyre, J. R., 1991: A fast radiative transfer model for satellite sounding systems. ECMWF Tech. Memo., 176, 28 pp.

Guillou, C., S. J. English, C. Prigent, and D. C. Jones, 1996: Passive microwave airborne measurements of the sea surface response at 89 and $157 \mathrm{GHz}$. J. Geophys. Res., 101, 37753788.

Jiang, J. H., and D. L. Wu, 2004: Ice and water permittivities for millimeter and submillimeter remote sensing applications. Atmos. Sci. Lett., 5, 146-151.

Kessler, E., 1969: On the Distribution and Continuity of Water Substance in Atmospheric Circulation. Meteor. Monogr., No. 32, Amer. Meteor. Soc., 84 pp.

Kummerow, C., and Coauthors, 2001: The evolution of the Goddard profiling algorithm (GPROF) for rainfall estimation from passive microwave sensors. J. Appl. Meteor., 40, 18011820.

Lafore, J.-P., 1998: The Méso-NH atmospheric simulation system. Part I: Adiabatic formulation and control simulations. Ann. Geophys., 16, 90-109.

Lin, Y.-L., R. D. Farley, and H. D. Orville, 1983: Bulk parameterization of snow field in a cloud model. J. Climate Appl. Meteor., 22, 1065-1092.

Liu, G., 2004: Approximation of single scattering properties of ice and snow particles for high microwave frequencies. J. Atmos. Sci., 61, 2441-2456.

Manabe, T., H. J. Liebe, and G. A. Hufford, 1987: Complex permittivity of water between 0 and 30 THz. Proc. 12th Int. Conf. on Infrared and Millimeter Waves, Orlando, FL, Institute of Electrical and Electronic Engineers, 229-230.

Matrosov, S. Y., R. F. Renking, R. A. Kropfti, and B. W. Bartram, 1996: Estimation of ice hydrometeor types and shapes from radar polarization measurements. J. Atmos. Oceanic Technol., 13, 85-96.

Mätzler, C., Ed., 2006: Thermal Microwave Radiation: Applications for Remote Sensing. IET Electromagnetic Waves Series 52, Institution of Engineering and Technology, $555 \mathrm{pp}$.

Mishchenko, M. I., 1991: Light scattering by randomly oriented axially symmetric particles. J. Opt. Soc. Amer., 8, 871-882.

_ 1993: Light scattering by size/shape distributions of randomly oriented axially symmetric particles of a size comparable to a wavelength. Appl. Opt., 32, 4652-4666.

- 2000: Calculation of the amplitude matrix for a nonspherical particle in a fixed orientation. Appl. Opt., 39, 1026-1031.

Pardo, J. R., J. Cernicharo, and E. Serabyn, 2001a: Atmospheric transmission at microwaves (ATM): An improved model for $\mathrm{mm} / \mathrm{submm}$ applications. IEEE Trans. Antennas Propag., 49, 1683-1694.

$\longrightarrow,-$, and $-2001 \mathrm{~b}$ : Submillimeter atmospheric transmission measurements on Mauna Kea during extremely dry El Nino conditions: Implications for broadband opacity contributions. J. Quant. Spectrosc. Radiat. Transfer, 68, 419-433.

_- M. Wiedner, E. Serabyn, C. D. Wilson, C. Cunningham, R. E. Hills, and J. Cernicharo, 2004: Side-by-side comparison of Fourier transform spectroscopy and water vapor radiometry as tools for the calibration of $\mathrm{mm} / \mathrm{submm}$ ground-based observatories. Astrophys. J. Suppl., 153, 363-367.

_, E. Serabyn, M. C. Wiedner, and J. Cernicharo, 2005: Measured telluric continuum-like opacity beyond $1 \mathrm{THz} . J$. Quant. Spectrosc. Radiat. Transfer, 96, 537-545.

Pinty, J.-P., and P. Jabouille, 1998: A mixed-phase cloud parameterization for use in mesoscale non-hydrostatic model: Simulations of a squall line and of orographic precipitations. Preprints, Conf. on Cloud Physics, Everett, WA, Amer. Meteor. Soc., 217-220.

Prigent, C., W. B. Rossow, and E. Matthews, 1997: Microwave land surface emissivities estimated from SSM/I observations. J. Geophys. Res., 102, 21 867-21 890.

—, J. R. Pardo, M. I. Mishchenko, and W. B. Rossow, 2001: Microwave polarized signatures generated within cloud systems: Special Sensor Microwave Imager (SSM/I) observations interpreted with radiative transfer simulations. J. Geophys. Res., 106, 28 243-28 258.

_ F. Chevallier, F. Karbou, P. Bauer, and G. Kelly, 2005a: AMSU-A land surface emissivity estimation for numerical weather prediction assimilation schemes. J. Appl. Meteor., 44, 416-426.

, E. Defer, J. R. Pardo, C. Pearl, W. B. Rossow, and J. P. Pinty, 2005b: Relations of polarized scattering signatures observed by the TRMM Microwave Instrument with electrical processes in cloud systems. Geophys. Res. Lett., 32, L04810, doi:10.1029/2004GL022225.

_ I. Meirold-Mautner, F. Aires, C. J. Walden, N. Viltard, and O.-Z. Zanife, 2005c: Study of the potential of sub-millimeter wave observations for precipitation retrieval. ESTEC Contract Rep. 18054/04/NL/FF (midterm report), 89 pp.

Ryzhkov, A. V., D. S. Zrnic, and B. A. Gordon, 1998: Polarimetric method for ice water content determination. J. Appl. Meteor., 37, 125-134.

Skofronick-Jackson, G., A. J. Gasiewski, and J. R. Wang, 2002: Influence of microphysical cloud parameterizations on microwave brightness temperatures. IEEE Trans. Geosci. Remote Sens., 40, 187-196.

Steppeler, J., G. Doms, U. Schättler, H. W. Bitzer, A. Gassmann, U. Damrath, and G. Gregoric, 2003: Meso-gamma scale fore- 
cast using the non-hydrostatic model LM. Meteor. Atmos. Phys., 82, 75-96.

Ulaby, F. T., R. K. Moore, and A. K. Fung, 1986: Microwave Remote Sensing: Active and Passive. Artech House, 2162 pp.

Vivekanandan, J., V. N. Bringi, M. Hagen, and P. Meisehmer, 1994: Polarimetric radar studies of atmospheric ice particles. IEEE Trans. Geosci. Remote Sens., 32, 1-10.

Warren, S. G., 1984: Optical constants of ice from the ultraviolet to the microwave. Appl. Opt., 23, 1206-1225.
Wicker, L. J., and W. C. Skamarock, 1998: A time-splitting scheme for the elastic equations incorporating second-order RungeKutta time differencing. Mon. Wea. Rev., 126, 1992-1999.

Wiedner, M., C. Prigent, J. R. Pardo, O. Nuissier, J.-P. Chaboureau, J.-P. Pinty, and P. Mascart, 2004: Modeling of passive microwave responses in convective situations using output from mesoscale models: Comparison with TRMM/TMI satellite observations. J. Geophys. Res., 109, D06214, doi:10.1029/2003JD004280. 